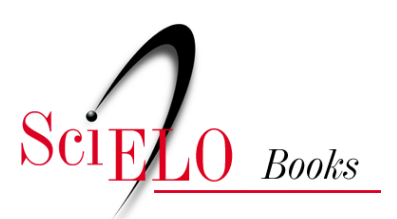

\title{
Notas sobre a questão da superação da metafísica em Merleau- Ponty
}

\author{
Antonio Balbino Marçal Lima
}

\section{SciELO Books / SciELO Livros / SciELO Libros}

LIMA, ABM., org. Notas sobre a questão da superação da metafísica em Merleau-Ponty. In: Ensaios sobre fenomenologia: Husserl, Heidegger e Merleau-Ponty [online]. Ilhéus, BA: Editus, 2014, pp. 119-124. ISBN 978-85-7455-444-0. Available from SciELO Books <http://books.scielo.org>.

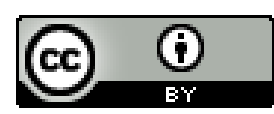

All the contents of this work, except where otherwise noted, is licensed under a Creative Commons Attribution $\underline{4.0 \text { International license. }}$

Todo o conteúdo deste trabalho, exceto quando houver ressalva, é publicado sob a licença Creative Commons Atribição 4.0.

Todo el contenido de esta obra, excepto donde se indique lo contrario, está bajo licencia de la licencia Creative Commons Reconocimento 4.0. 


\title{
Notas sobre a questão da superação da metafísica em Merleau-Ponty
}

\author{
Antonio Balbino Marçal Lima
}

1 A questão da superação da metafísica nasceu com Dilthey e se dividiu em dois traços distintos, propostos por Heidegger e Carnap (STEIN, 1991).

1.1 Heidegger, influenciado por Nietzsche, moldou uma forma muito original de superação da metafísica ao afirmar que, até seu tempo, toda a história da ontologia não passara de uma teologia, e com os neokantianos, caíra numa teoria do conhecimento.

1.1.1 A expressão "superação da metafísica" surge apenas em seus textos na segunda metade da década de 1930, mais precisamente nos seus cursos sobre Nietzsche entre 1936 e 1941. Nesse período Heidegger prolonga e aprofunda, em especial, dois aspectos que já lhe eram familiares: a relação entre Ser e história e a ideia de metafísica como esquecimento do Ser. Contudo, há um elemento que ele abandona e se torna basilar: a pretensão de refundar a metafísica ocidental.

1.2 Por outro lado, Carnap entende a questáo de forma diferente, e propõe uma solução num ensaio de 1932, A superação 
da metafísica pela análise lógica da linguagem. Para Carnap, assim como para os seus seguidores, a metafísica constitui-se de proposiçôes destituídas de sentido, desse modo, a análise lógica de suas proposiçôes levará à sua superação.

1.3 Merleau-Ponty, que viveu na época do surgimento deste movimento bifurcado, em sua obra Fenomenologia da percepção elabora uma crítica às tradiçóes idealistas e realistas, bem como à ideia de que o homem possa ser fundamento, isto é, um princípio explicativo em substituição aos outros. $\mathrm{O}$ projeto de Merleau-Ponty é retomar o homem concreto, capaz de virar-se para este mundo e capaz de pensá-lo.

1.3.1 Tanto na Estrutura do Comportamento (1942) como na Fenomenologia da Percepção (1945), o projeto de Merleau-Ponty é o mesmo: entender as relaçóes entre a consciência e a natureza, interior e exterior, entendendo a natureza não só a realidade física, mas as determinaçóes orgânicas, psicológicas e sociais.

1.3.2 A discussão inicial de Merleau-Ponty leva em conta os resultados da psicologia da Gestalt, que, para ele, nos faz ver não mais uma inteligência que constrói o mundo, mas um ser que nele está lançado e, a ele, também está ligado por um elo natural. Segundo Merleau-Ponty, a psicologia da Gestalt nos ensina de novo a observar este mundo, com o qual estamos em contato, através de toda superfície de nosso ser, enquanto a psicologia clássica renunciava ao mundo vivido em favor daquele que a inteligência conseguia construir (MERLEAU-PONTY, 1983, p. 110). 
1.3.3 Segundo a leitura que Merleau-Ponty faz das pesquisas da Gestalttheorie, para que possam ser compreendidos, os fenômenos perceptivos náo dependem de uma representação "anímica" exterior aos elementos sensíveis de nossa experiência. A descoberta da vinculação entre a "figura" (percebida) e o "contexto" (em que nosso corpo se situa ao percebê-la) demonstra que os fenômenos estão indissociavelmente ligados às nossas experiências. Mais precisamente, aquela descoberta revela que os fenômenos estão inexoravelmente vinculados à organizaçáo espontânea desencadeada por nosso corpo junto aos dados sensíveis. Segundo Bonomi (1974), Merleau-Ponty afirma que o ser não se apresenta como positividade, plenitude, mas se define como um campo em que se abrem dimensionalidades diversas, em que todo ente é figura-sobre-fundo, relevo em relação a uma profundidade. Para Chauí (2002), o trabalho filosófico de Merleau-Ponty está empenhado numa interrogação permanente da razão e da experiência para conduzi-las a uma racionalidade alargada, capaz de alcançar o universal não como "universal de sobrevoo", ponto de vista abstrato e exterior ao mundo, mas como "universal lateral ou oblíquo", que permite compreender aquilo que em nós e nos outros excede a razão.

1.3.4 A radicalização dessa interrogação levou Merleau-Ponty da fenomenologia para a busca de uma ontologia do Ser Bruto, fonte da experiência e da razão antes que o pensamento reflexivo delas se aproprie. Mas é em $O$ olho e o espirito que Merleau-Ponty coloca a dimensão do ser primordial, bruto, anterior a toda elaboraçáo reflexiva. O ponto de incidência da sua interrogação filosófica será esta presença originária do que "hâ", ainda não tematizado. Trata-se, então, de recolocar-se na zona 
do há preliminar, de nosso contato originário com o ser, onde o saber não operou ainda a cisão entre o "subjetivo" e o "objetivo" e no qual se institui uma primeira estratificação de sentido, sobre a qual todas as outras poderão depois ser edificadas.

1.3.5 Na última parte da Fenomenologia da percep̧̧ão, Merleau-Ponty afirma o caráter central do problema da contingência, que trata, segundo Bonomi (1974), de uma contingência ontológica, isto é, não de uma simples 'lacuna' que uma investigação exaustiva deveria resolver, descobrindo suas razóes ocultas, mas do ser-aí do mundo, face ao qual o necessário e o possível são apenas modalidades particulares e não fundantes.

1.3.6 É nessa perspectiva que Merleau-Ponty analisa a consciência, não só como uma atividade intencional, mas um eu posso no qual vêm se entrelaçar a práxis e a percepção: a consciência do objeto percebido, por exemplo, o permanecer de sua forma ou cor sob condiçōes perceptivas diversas, supóe o movimento do sujeito que percebe. Esse modo de ver a percepçáo afasta a clássica questáo filosófica que se refere à existência do objeto em si. Porém, a percepçấo náo esgota o percebido, uma vez que ela recorta perspectivas segundo certo estilo do percebido.

1.3.7 Para Merleau-Ponty, a percepção oferece verdades como presenças. Isso significa que nossa relação com o mundo não é a de um pensador com um objeto do pensamento; não significa, também, que a unidade da coisa percebida, enquanto percebida por muitas consciências, seja a do tipo daquela dada na proposiçấo. Presença é o estar no próprio momento em que as coisas, as verdades, os valores se constituem para 
nós. É o momento em que o sentido se faz. A presença se constitui como um logos nascente, pois é na experiência perceptiva que a unidade do mundo se constitui, que a existência é sentida como o viver o presente do corpo encarnado.

1.4 Hipótese. É comum, entre os comentadores de Merleau-Ponty, dividir seu pensamento em duas fases, a saber, a fase fenomenológica, presente em $A$ estrutura do comportamento e Fenomenologia da percepção, e a fase ontológica, caracterizada pela ontologia do Ser Bruto, presente principalmente em $O$ visivel e o invisivel. Em outras palavras, considera-se que há uma evolução da noção de corpo para a noção de carne. Nossa hipótese consiste em mostrar que $A$ Fenomenologia $d a$ Percepção, ao fundar a ontologia do sensível como resposta à insuficiência de uma filosofia que postula uma consciência plena, elabora, além de uma crítica à metafísica, a tentativa de sua superação.

\section{Referências}

BORNHEIM, G. Metafísica e finitude. São Paulo:

Perspectiva, 2001.

BONOMI, A. Fenomenologia e estruturalismo. São Paulo: Perspectiva, 1974.

CHAUÍ, Marilena de S. Experiência do Pensamento:

ensaios sobre a obra de Merleau-Ponty. Sáo Paulo: Martins Fontes, 2002. 
DARTIGUES, André. O que é a fenomenologia. 3. ed. Tradução. Maria José J. G. de Almeida. São Paulo: Editora Moraes, 1992.

HEIDEGGER, Martin. Ser e tempo. Tradução Márcia Sá Cavalcante Schuback Petrópolis: Vozes, 2006.

MERLEAU-PONTY, M. Fenomenologia da percepção. Trad. Carlos Alberto Ribeiro de Moura. São Paulo: Martins Fontes, 1999.

A estrutura do comportamento. Trad. José de A. Correa. B. Horizonte-MG: Interlivros, 1975.

O visível e o invisível. 3 ed. Trad. José A. Gianotti e Armando M. de Oliveira. São Paulo: Perspectiva, 1992.

. O olho e o espírito. In: Merleau-Ponty. São Paulo: Nova Cultural, 1989 a.

. O metafísico no homem. In: Merleau-Ponty. São Paulo: Nova Cultural, 1989 b.

O cinema e a nova psicologia. In: XAVIER, Ismail (org.). A experiência do cinema. Rio de Janeiro: Graal, 1983.

STEIN, Ernildo. Notas de Tradução. In: MERLEAUPONTY, M. Textos selecionados. Sáo Paulo: Abril Cultural, 1991. (Coleção Os Pensadores). 


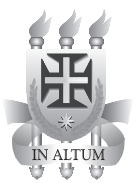

IMPRENSA UNIVERSITÁRIA

Impresso na gráfica da Universidade Estadual de Santa CruZ - Ilhéus-BA 